\title{
Color Centers Formation in Lithium Fluoride Nanocubes Doped with Different Elements
}

\author{
Numan Salah, ${ }^{1}$ Saeed S. Babkair, ${ }^{2}$ and Ameer Azam ${ }^{1}$ \\ ${ }^{1}$ Center of Nanotechnology, King Abdulaziz University, Jeddah 21589, Saudi Arabia \\ ${ }^{2}$ Center of Nanotechnology, Department of Physics, Faculty of Science, King Abdulaziz University, Jeddah 21589, Saudi Arabia
}

Correspondence should be addressed to Numan Salah; nsalah@kau.edu.sa

Received 27 September 2013; Accepted 28 November 2013

Academic Editor: Hongchen Chen Gu

Copyright (C) 2013 Numan Salah et al. This is an open access article distributed under the Creative Commons Attribution License, which permits unrestricted use, distribution, and reproduction in any medium, provided the original work is properly cited.

\begin{abstract}
Nanocrystalline cubes of pure and doped LiF material were fabricated. They were doped with $\mathrm{Cu}, \mathrm{Ag}, \mathrm{Dy}, \mathrm{Tb}$, and Eu and studied for their PL properties. Shape of the obtained nanocubes was found to be modified by introducing dopants into the host of LiF. The crystallinity was also decreased by increasing the concentration of these dopants (i.e., Eu and Tb). These impurities could induce exothermic peaks at around $250^{\circ} \mathrm{C}$ in the measured DSC curves. Moreover, incorporating such impurities into the host of LiF was found to enhance intensity of the broad band at $370-550 \mathrm{~nm}$ that was observed in the pure one. Extra sharp emissions were also observed in $\mathrm{Eu}$ and $\mathrm{Tb}$ doped samples. These results showed that the active color centers created in pure LiF nanocubes can be enriched/enhanced by these impurities, mainly Eu and $\mathrm{Tb}$. This implies that these nanocubes might be useful in the development of optical devices and advanced color center laser.
\end{abstract}

\section{Introduction}

Lithium fluoride ( $\mathrm{LiF}$ ) single crystal as well as doped with proper activators is a highly sensitive phosphor used in several applications such as integrated optics, color center laser, and radiation dosimetry. It has the highest UV transmission of all materials and is used for X-ray monochromator plates where its lattice spacing makes it the most suitable analysis crystal. It has low effective atomic number (8.14), which is sufficiently close to that of the biological tissue (7.4). This material is sensitive to ionization radiation, especially when doped with proper activators. $\mathrm{LiF}$ doped with $\mathrm{Mg}, \mathrm{Cu}$, and $\mathrm{P}$ is found to be the most sensitive material for ionizing radiations using thermoluminescence (TL) technique. This material was first synthesized and reported in 1978 by Nakajima et al. [1]. Thereafter, many research groups produced the phosphor using different procedures and studied its characteristics [2-7]. Other workers have investigated the role of impurities in the $\mathrm{TL}$ of $\mathrm{LiF}: \mathrm{Mg}, \mathrm{Cu}$, and $\mathrm{P}$ phosphor [6-11]. The nanostructure form of $\mathrm{LiF}: \mathrm{Mg}, \mathrm{Cu}$, and $\mathrm{P}$ was prepared for the first time by Salah et al. [12] and studied for its TL response. They found that this material in nanoform is sensitive to gamma rays in a wide range of exposures ( $0.1 \mathrm{~Gy}-$ $10 \mathrm{kGy})$.

Color center is a type of crystallographic defect in which an anionic vacancy in a crystal is filled by one or more electrons. In fact, this depends on the charge of the missing ion in the crystal. When a compound is heated to high temperature, the electrons get excited and get displaced from their respective positions in the crystal structure leaving behind some electrons in the vacated spaces. This leads to the phenomenon of coloring of compounds. Formation of color centers in LiF by irradiation was reported and studied in detail by several authors [13-17]. However, reports on formation and modification of color centers in LiF without irradiation rarely appeared. Such color centers were also not studied in the nanostructure form of LiF. It has been reported that the large specific surface area of nanostructured materials can increase the absorption and then the quantum yields [18]. Recent study by Alharbi et al. [19] showed an excellent property in LiF nanostructure, which is the formation of a broad band at around $370-550 \mathrm{~nm}$ without irradiation. This band was attributed to the color centers induced in the host of LiF due to oxygen defects, which might be created during 
the synthesis process. They have produced size-controlled nanocubes of pure and silver doped LiF by the chemical coprecipitation method. Doping this material with Ag ion was found to enhance the PL property of LiF nanocubes. Therefore, it is very interesting to further study the effect of other impurities such as rare earths and other elements on the PL property of this important material.

In this work, we report on producing nanocrystalline cubes of pure and cupper $(\mathrm{Cu})$, silver $(\mathrm{Ag})$, dysprosium (Dy), terbium $(\mathrm{Tb})$, and europium $(\mathrm{Eu})$ doped LiF by the chemical coprecipitation method. The as-synthesized samples were characterized by scanning electron microscopy (SEM), Xray diffraction (XRD), and differential scanning calorimetry (DSC) and studied for their photoluminescence (PL) properties. The results show that the shape and crystallinity of these nanocubes were modified by introducing dopants into the host of LiF. These impurities were found to enhance intensity of the broad band of the pure sample. Extra sharp emissions were also observed in Eu and Tb doped samples. These results showed that the active color centers created in pure $\mathrm{LiF}$ nanocubes can be enriched/enhanced by these impurities, mainly Eu and $\mathrm{Tb}$. This suggests that these nanocubes might be useful in several applications such as optical devices and color center laser.

\section{Experimental Details}

Nanocrystalline cubes of pure and cupper $(\mathrm{Cu})$, silver $(\mathrm{Ag})$, dysprosium (Dy), terbium (Tb), and europium (Eu) doped LiF were produced by the chemical co-precipitation method as adopted earlier by Alharbi et al. [19]. They were synthesized using AR grade chemicals at room temperature. Water and ethanol were used as solvents at a ratio of $0.1: 1$. Initially, the desired concentration of lithium chloride $(\mathrm{LiCl})$ was dissolved in triply distilled deionized water. The normality of the solution was $0.2 \mathrm{~N}$. Then, this solution was mixed with ammonium fluoride $\left(\mathrm{NH}_{4} \mathrm{~F}\right)$ solution $(0.2 \mathrm{~N})$ stoichiometrically. The solution of $\mathrm{NH}_{4} \mathrm{~F}$ was added to the solution of $\mathrm{LiCl}$ drop wise with continuous stirring. The precipitate was filtered out and washed several times with distilled water. The powder samples, thus obtained, were dried at $343 \mathrm{~K}$ in an oven for $2 \mathrm{~h}$. The used impurities in this study were added in their chloride forms. A typical concentration of these impurities, that is, 0.5 mole\% was used in LiF samples except those doped with Eu and $\mathrm{Tb}$, where samples with different concentrations of dopants were obtained. These concentrations are $0.1,0.2$, 0.5 , and 1 mole $\%$. In a typical case, the desired concentration of the impurity, that is, $\mathrm{DyCl}_{3} \cdot 6 \mathrm{H}_{2} \mathrm{O}$ was added to the solution of $\mathrm{LiCl}$ and stirred for $1 \mathrm{~h}$ before adding the solution of $\mathrm{NH}_{4} \mathrm{~F}$ as mentioned above.

The as-synthesized LiF powder samples were characterized by XRD, using an Ultima-IV (Rigaku, Japan) diffractometer with $\mathrm{Cu} \mathrm{K} \alpha$ radiation, while the morphology of these samples was studied by SEM using a field emission scanning electron microscopy (FESEM), JSM-7500 F (JEOLJapan) operated at $15 \mathrm{kV}$. Photoluminescence (PL) emission spectra were recorded at an excitation wavelength of $325 \mathrm{~nm}$ using a fluorescence spectrofluorophotometer, model RF5301 PC, Shimadzu, Japan. The measurement was performed at room temperature. The thermal behavior in pure $\mathrm{LiF}$ and $\mathrm{Eu}, \mathrm{Tb}$ doped samples was studied under nonisothermal measurements by using a Shimadzu DSC-60 instrument. Typically, $5 \mathrm{mg}$ of sample in powder form was sealed in standard aluminum sample pans and heated at a heating rate of $10^{\circ} \mathrm{C} / \mathrm{min}$. The temperature precision of this equipment is $\pm 0.1 \mathrm{~K}$.

\section{Results and Discussion}

SEM images of the as-synthesized pure and $\mathrm{Eu}$ doped $\mathrm{LiF}$ powder samples are presented in Figures 1(a)-1(e). The pure sample has nanocubes with sizes in the range of $40-90 \mathrm{~nm}$ (Figure 1(a)). This figure shows that the shapes of these nanocubes were slightly modified by introducing Eu as impurity into the LiF host (Figures 1(b)-1(e)). This modification is clearly observed in shape of Eu doped samples by increasing the concentration of this impurity from 0.1 to 1 mole $\%$. The modification includes a loss in uniformity of the nanocubes' structure and showing irregular shapes. Moreover, with increasing the concentration of $\mathrm{Eu}$ in $\mathrm{LiF}$, host small shiny nanorods are formed. These nanorods are clearly observed at higher concentrations of Eu as shown in Figure 1(e). Similar trend is also observed in the $\mathrm{Tb}$ doped samples (Figures 2(a)-2(d)), mainly the formation of irregular shapes. These modifications in shapes of these nanocubes by adding impurities, that is, $\mathrm{Eu}$ and $\mathrm{Tb}$ might be due to the formation of new phases or other compounds. It is possible that an interruption in the crystal structure of $\mathrm{LiF}$ is occurred by inducing the dopant ions into the host and causing irregularity in these crystals. Moreover, small portion of these doped crystals might be able to form rod structures instead of cubes as shown in Eu doped samples (Figure 1(e)). The effect of an impurity in the nanoscale crystals is expected to be different than that in a single big crystal (in the bulk or microsize). In the nanoscale crystals or nanocrystalline, the effect will be more visible.

XRD patterns of the as-synthesized pure and Eu doped LiF samples are shown in Figure 3 (curves (a), (b), (c), (d), and (e)). The XRD result of pure sample (curve (a)) shows several diffracted peaks with hkl values indicating a complete crystalline structures in a griceite phase. Moreover, there is significant broadening in the XRD peaks, which implies that the samples are nanosized (in cubic forms). This result is similar to that reported earlier by Alharbi et al. [19]. However, the crystallinity of these nanocubes decreases by inducing Eu as a dopant in the host of LiF (Figure 3, curves (b), (c), (d), and (e)). This crystallinity systematically decreases by increasing the concentration of Eu. Furthermore, by inducing Eu into the host of LiF, small diffracted peak is observed at around $2 \theta=33^{\circ}$. This peak might be due to the formation of small amount of europium oxide (DB card number 00-046-0427) (Figure 1(e)). Similarly, Tb doped samples show almost the same trend, where oxide compound (or other compound) of terbium might get formed (Figure 4 curves (a), (b), (c), (d), and (e)). The result shown in XRD study is in agreement with that shown in SEM images. The formation of oxide compounds of these impurities might be the reason for forming small shiny nanorods. 


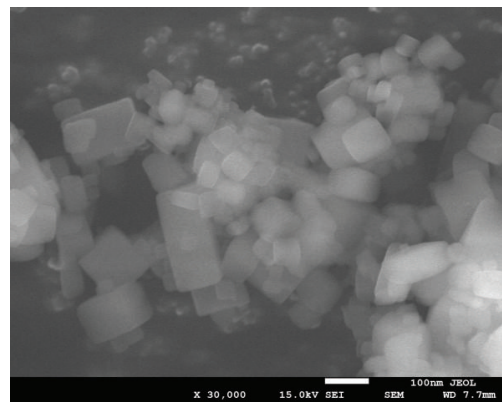

(a)

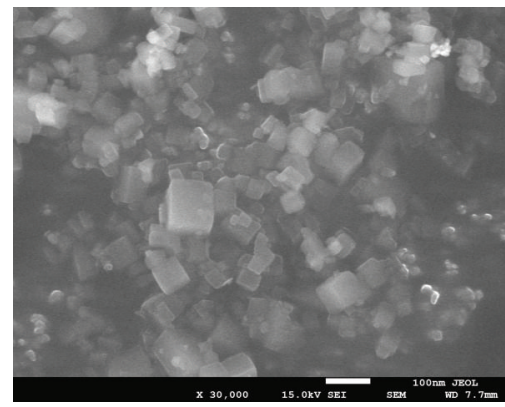

(b)

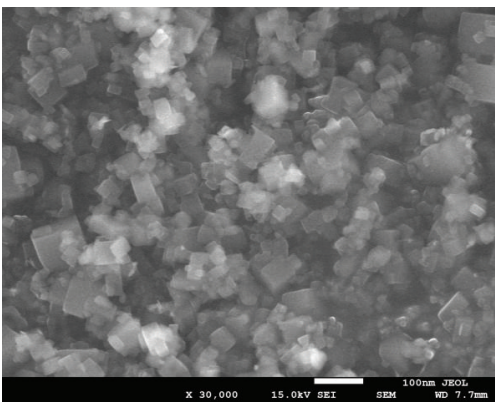

(c)

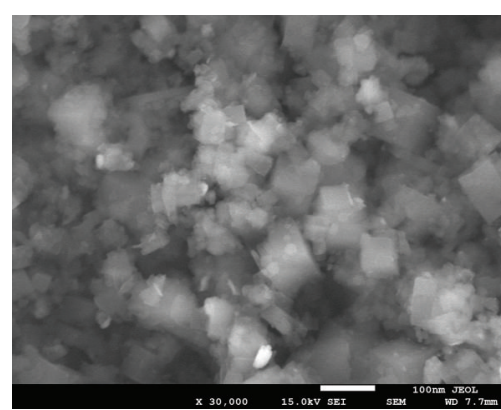

(d)

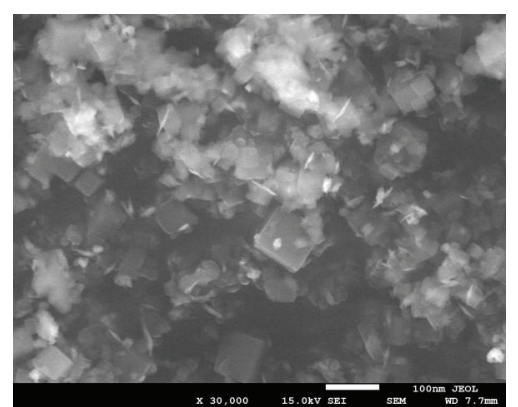

(e)

FIGURE 1: SEM images of the as-synthesized nanocubes of (a) pure LiF and Eu doped samples at different concentrations: (b) $0.1 \mathrm{~mole} \%$, (c) $0.2 \mathrm{~mole} \%$, (d) $0.5 \mathrm{~mole} \%$, and (e) $1 \mathrm{~mole} \%$.

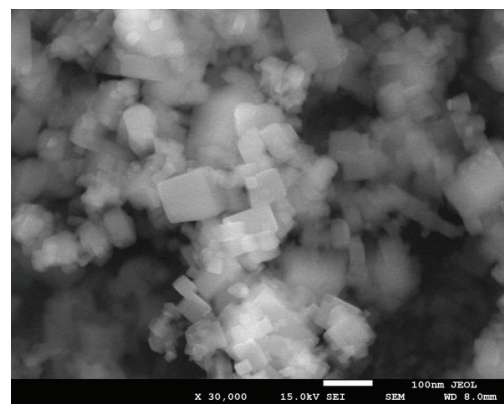

(a)

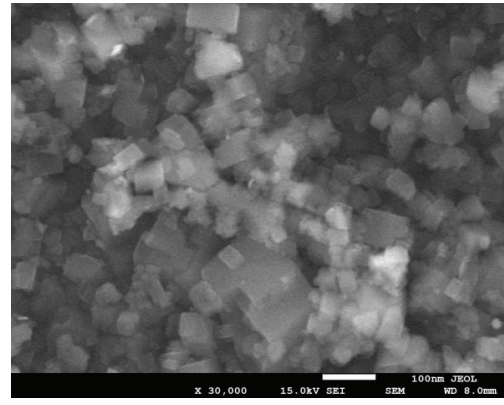

(c)

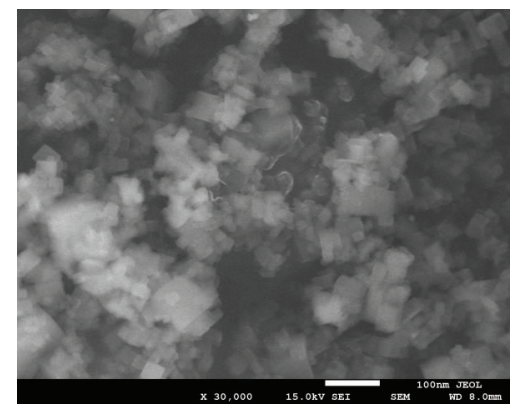

(b)

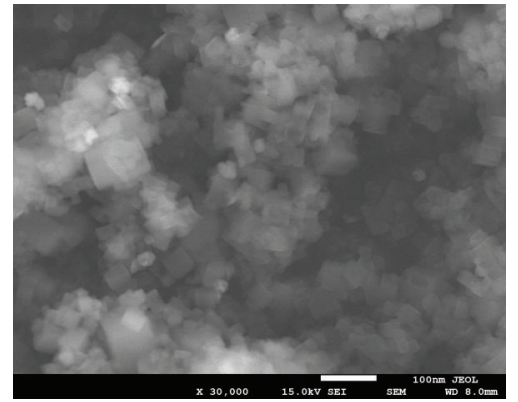

(d)

FIGURE 2: SEM images of the as-synthesized nanocubes of LiF doped with Tb at different concentrations: (a) $0.1 \mathrm{~mole} \%$ (b) $0.2 \mathrm{~mole} \%$, (c) $0.5 \mathrm{~mole} \%$, and (d) 1 mole $\%$. 


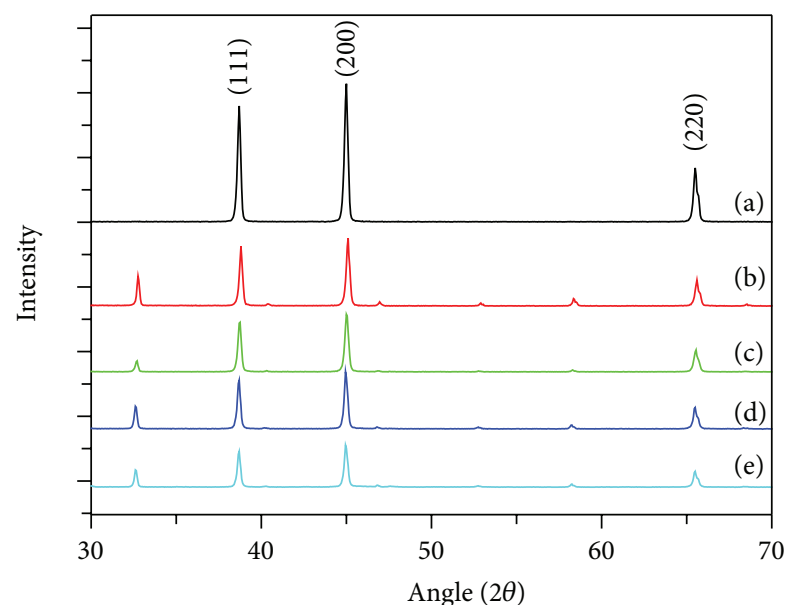

FIGURE 3: XRD pattern of the as-synthesized nanocubes of (a) pure $\mathrm{LiF}$ and Eu doped samples at different concentrations: (b) $0.1 \mathrm{~mole} \%$, (c) 0.2 mole $\%$, (d) 0.5 mole $\%$, and (e) 1 mole $\%$.

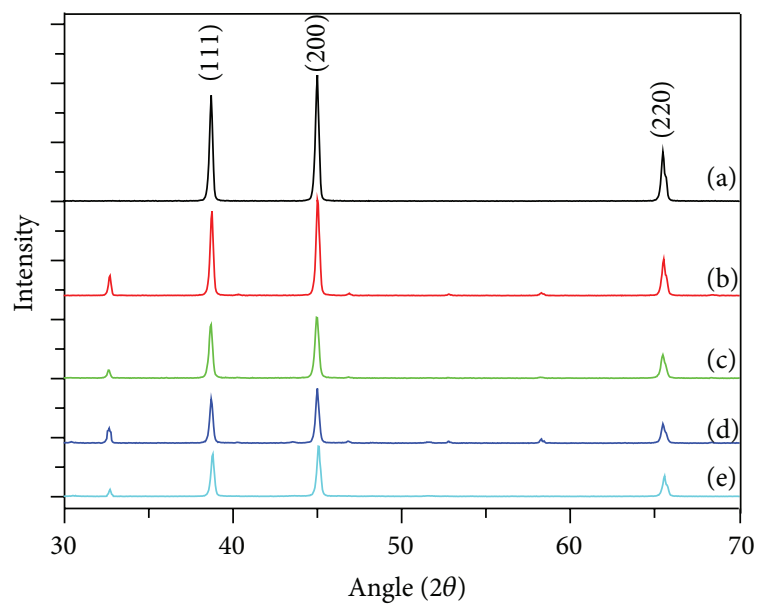

FIGURE 4: XRD pattern of the as-synthesized nanocubes of (a) pure $\mathrm{LiF}$ and $\mathrm{Tb}$ doped samples at different concentrations: (b) $0.1 \mathrm{~mole} \%$, (c) $0.2 \mathrm{~mole} \%$, (d) $0.5 \mathrm{~mole} \%$, and (e) $1 \mathrm{~mole} \%$.

Differential scanning calorimetry (DSC) measurements for pure and $\mathrm{Eu}$ and $\mathrm{Tb}$ doped samples at typical concentrations are shown in Figure 5 (curves (a), (b), and (c), resp.). The DSC curve of pure LiF nanocubes (curve (a)) has no endo- or exothermic peaks. This is a clear indication that pure LiF has only a single phase. The samples doped with $\mathrm{Eu}$ and $\mathrm{Tb}$ show one prominent exothermic peak at around $250^{\circ} \mathrm{C}$. The existence of this peak in the doped samples might be of the oxide structure of the used impurity as mentioned above. This oxide structure has different crystal structure rather than cubes. This result corroborates the result obtained by SEM and XRD.

Figure 6 shows the PL emission spectra of pure and $\mathrm{Cu}$, $\mathrm{Ag}, \mathrm{Dy}, \mathrm{Tb}$, and Eu doped LiF nanocubes, curves (a), (b), (c), (d), (e), and (f), respectively. The emission spectrum of pure sample (curve (a)) shows a broad band in the range of $370-550 \mathrm{~nm}$. This band might be assigned to the $F_{2}$ and $F_{3}^{+}$ color centers (two electrons captured by two and three anion vacancies, resp.) [19]. These centers could be induced in the

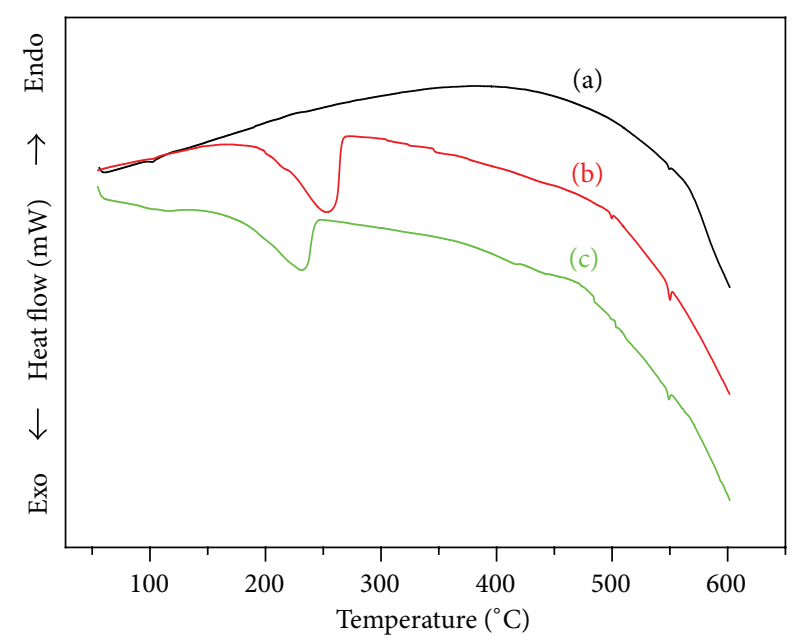

(a) Pure LiF nanocubes

(b) Eu doped LiF nanocubes

(c) $\mathrm{Tb}$ doped $\mathrm{LiF}$ nanocubes

FIGURE 5: DSC plot for the as-synthesized nanocubes of LiF: (a) pure, (b) Eu doped, and (c) Tb doped samples at concentrations of 0.5 mole $\%$.

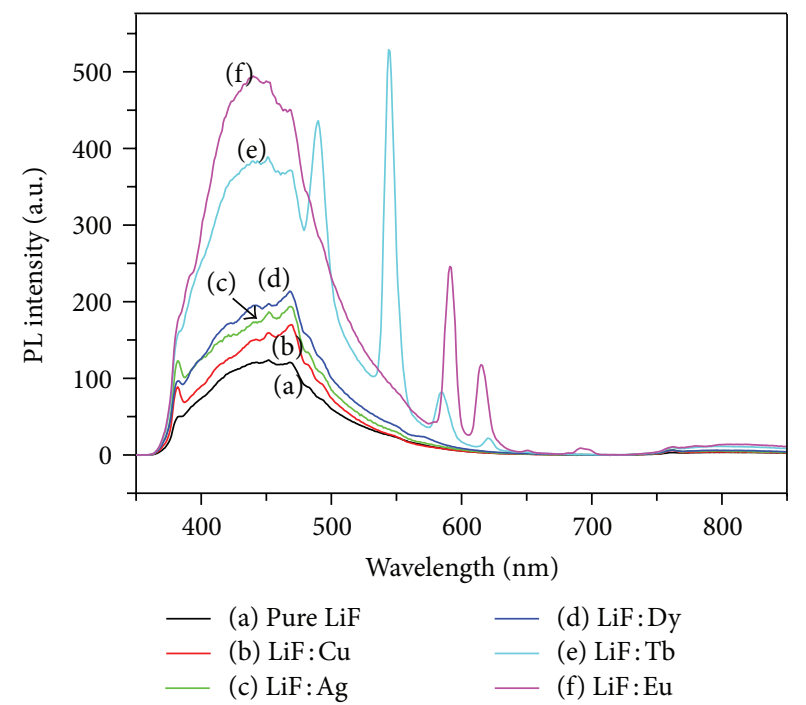

FIGURE 6: PL emission spectra of the as-synthesized nanocubes of pure and doped $\mathrm{LiF}$ samples with different impurities at a concentration of $0.5 \mathrm{~mole} \%$.

host of $\mathrm{LiF}$ due to oxygen defects, which might be created during the synthesis process. It has been reported [20] that oxygen defects/contaminations can lead to such emissions, but at the higher wavelength side of the visible region. In the present LiF nanocubes, the shift in the emission band to the lower wavelength might be due to widening in the band gap of the material as a result of reducing the particle size to the nanoscale.

The emission spectra of $\mathrm{Cu}, \mathrm{Ag}$, and Dy doped samples (Figure 6, curves (b), (c), and (d), resp.) are almost similar to that of the pure one (Figure 6, curve (a)), but with further 
PL enhancement. The PL emission spectra of $\mathrm{Tb}$ and $\mathrm{Eu}$ doped samples (Figure 6, curves (e) and (f)) show strong enhancement in intensity of the broad band at $370-550 \mathrm{~nm}$, with the emergence of extra sharp emissions. The emission spectrum of $\mathrm{Tb}$ doped sample shows two strong sharp emissions peaking at 488 and $544 \mathrm{~nm}$ along with two smaller ones at around 585 and $620 \mathrm{~nm}$. These bands are the well-known emissions of $\mathrm{Tb}^{3+}$ ions. They can be assigned to the ${ }^{5} \mathrm{D}_{4} \rightarrow$ ${ }^{7} \mathrm{~F}_{6},{ }^{5} \mathrm{D}_{4} \rightarrow{ }^{7} \mathrm{~F}_{5},{ }^{5} \mathrm{D}_{4} \rightarrow{ }^{7} \mathrm{~F}_{4}$, and ${ }^{5} \mathrm{D}_{4} \rightarrow{ }^{7} \mathrm{~F}_{3}$ transitions of $\mathrm{Tb}^{3+}$ ion, respectively [21-23]. In the Eu doped sample, the broad band at $370-550 \mathrm{~nm}$ has the highest PL intensity in association with two bands located at 590 and $615 \mathrm{~nm}$, which are the well-known emissions of $\mathrm{Eu}^{3+}$ ion [23]. The bands at 590 and $615 \mathrm{~nm}$ are due to ${ }^{5} \mathrm{D}_{0} \rightarrow{ }^{7} \mathrm{~F}_{1}$ and ${ }^{5} \mathrm{D}_{0} \rightarrow{ }^{7} \mathrm{~F}_{2}$ transitions of $\mathrm{Eu}^{3+}$ ion, respectively. Small hump at around $700 \mathrm{~nm}$ can also be seen, which can be attributed to ${ }^{5} \mathrm{D}_{0} \rightarrow$ ${ }^{7} \mathrm{~F}_{3}$ transition of $\mathrm{Eu}^{3+}$ ion. Ag doped LiF sample was studied earlier [19], but at different concentrations of Ag. The PL of this sample showed prominent emission at $420 \mathrm{~nm}$, which has been enhanced by increasing the concentration of $\mathrm{Ag}$ ions. The optimum value for the concentration of $\mathrm{Ag}$ to show maximum PL emission was found to be 0.08 mole\% [19]. This band could be assigned to the contribution from the surface resonance band of $\mathrm{Ag}[24,25]$. In the present work, a typical concentration of $0.5 \mathrm{~mole} \%$ for $\mathrm{Ag}$ ions was selected and included in this study for comparison propose, since the optimum values for other impurities were unknown.

The observed enhancement in intensity of the broad band at $370-550 \mathrm{~nm}$ by introducing impurities into the host of $\mathrm{LiF}$ (Figure 6) might be due to overlapping of the energy levels (color centers) of oxygen defects with those created by these impurities inside the band gap of LiF. Normally, $\mathrm{Ag}$ and $\mathrm{Cu}$ ions as impurities show their emissions at the blue region of the visible region [24-26]. In the present case, these emissions will overlap with that of oxygen defects leading to further enhancement. Dysprosium ion might get introduced into the host of $\mathrm{LiF}$ matrix in its $3+$ form $\left(\mathrm{Dy}^{3+}\right)$ and this ion is a wellknown activator mostly showing its emission in the visible region. This ion was reported by several authors to have two emissions at around 485 and $572 \mathrm{~nm}$ [27]. In the present Dy doped LiF sample, the first band might be included within the broad band at $370-550 \mathrm{~nm}$, while the second one is shown as a small hump at around $570 \mathrm{~nm}$ (Figure 6, curve (d)). Cupper ions might have been incorporated in their $1+$ form $\left(\mathrm{Cu}^{+}\right)$as reported earlier by Patil and Moharil [6], but as mentioned above the emission will be in the blue region [26]. Therefore, this emission might get included within the broad band at 370-550 nm and thus could show further PL enhancement.

PL emission spectra of pure LiF nanocubes and $\mathrm{Eu}$ doped samples (at different concentrations) are presented in Figure 7, curves (a), (b), (c), (d), and (e), respectively. This figure shows that the optimum value for the concentration of $\mathrm{Eu}$ in $\mathrm{LiF}$ host is $0.5 \mathrm{~mole} \%$. At this concentration, the intensity of the broad band at $370-550 \mathrm{~nm}$ is increased by a factor of approximately 4 compared with that of the pure sample. Beyond this concentration, the intensity decreases, which might be due to the PL quenching. This quenching normally occurs at the higher concentrations of dopants [28].

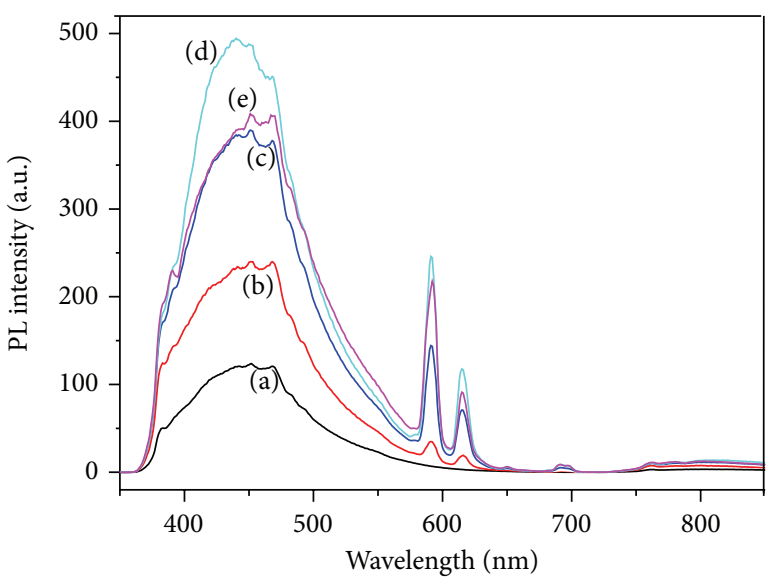

- (a) Pure LiF

Eu doped samples at concentrations of

- (b) $0.1 \mathrm{~mole} \%$

- (c) 0.2 mole $\%$

- (d) $0.5 \mathrm{~mole} \%$

- (e) 1 mole $\%$

FIgURE 7: PL emission spectra of the as-synthesized nanocubes of pure and Eu doped LiF samples at different concentrations.

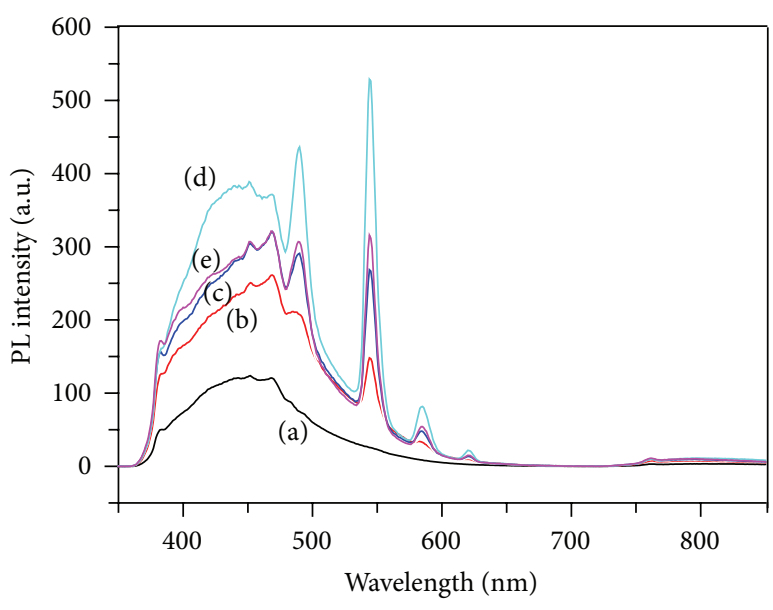

- (a) Pure LiF

$\mathrm{Tb}$ doped samples at concentrations of

— (b) $0.1 \mathrm{~mole} \%$

- (c) 0.2 mole $\%$

- (d) $0.5 \mathrm{~mole} \%$

- (e) $1 \mathrm{~mole} \%$

FIGURE 8: PL emission spectra of the as-synthesized nanocubes of pure and $\mathrm{Tb}$ doped $\mathrm{LiF}$ samples at different concentrations.

Similarly, $\mathrm{Tb}$ ions show maximum emissions at a concentration of 0.5 mole\% (Figure 8). The sharp band at $540 \mathrm{~nm}$ in $\mathrm{Tb}$ doped sample (at a concentration of $0.5 \mathrm{~mole} \%$ ) is strongly enhanced suggesting that this nanomaterial might have potential application as a monochromatic laser material.

From the application point of view, the results presented in this study show that pure nanocubes of LiF have active color centers without irradiation, which could be 
enriched/enhanced by Eu and $\mathrm{Tb}$ dopants. This implies that these nanocubes might be useful in the development of optical devices and advanced color center laser. Moreover, the method of producing this material in a nanoscale size is very simple and nonexpensive. These nanostructures are of great advantage due to the increase in the specific surface area, which is responsible for increasing the absorption and then the quantum yields.

\section{Conclusions}

In this work, we reported on fabricating nanocrystalline cubes of pure and doped LiF material. They were doped with $\mathrm{Cu}, \mathrm{Ag}, \mathrm{Dy}, \mathrm{Tb}$, and $\mathrm{Eu}$ and studied for their PL properties. Shape of the obtained nanocubes was found to be modified by introducing dopants into the host of LiF. The crystallinity was also decreased by increasing the concentration of these dopants, that is, Eu and $\mathrm{Tb}$. These impurities could induce exothermic peaks at around $250^{\circ} \mathrm{C}$ in the measured DSC curves. Moreover, incorporating such impurities into the host of LiF was found to enhance intensity of the broad band at $370-550 \mathrm{~nm}$ that was observed in the pure one. Extra sharp emissions were also observed in $\mathrm{Eu}$ and $\mathrm{Tb}$ doped samples. The optimal concentrations of Eu and $\mathrm{Tb}$ in LiF host for maximum emissions were found to be $0.5 \mathrm{~mole} \%$. These results showed that the active color centers created in pure $\mathrm{LiF}$ nanocubes can be enriched/enhanced by these impurities mainly Eu and $\mathrm{Tb}$. This implies that these nanocubes might be useful in the development of optical devices and advanced color center laser.

\section{Acknowledgment}

This project was funded by the Deanship of Scientific Research (DSR), King Abdulaziz University, Jeddah, under Grant no. 222/135/1433. The authors, therefore, acknowledge with thanks DSR technical and financial support.

\section{References}

[1] T. Nakajima, Y. Murayama, T. Matsuzawa, and A. Koyano, "Development of a new highly sensitive LiF thermoluminescence dosimeter and its applications," Nuclear Instruments and Methods, vol. 157, no. 1, pp. 155-162, 1978.

[2] D.-K. Wu, F.-Y. Sun, and H. A. Dai, "A high sensitivity LiF thermoluminescent dosimeter- $\mathrm{LiF}(\mathrm{Mg}, \mathrm{Cu}, \mathrm{P})$," Health Physics, vol. 46, no. 5, p. 1063, 1984.

[3] W. Shoushan, "The dependence of thermoluminescence response and glow curve structure of $\operatorname{LiF}(\mathrm{Mg}, \mathrm{Cu}, \mathrm{P})$ TL materials on $\mathrm{Mg}, \mathrm{Cu}, \mathrm{P}$ dopants concentration," Radiation Protection Dosimetry, vol. 25, no. 2, pp. 133-136, 1988.

[4] A. Horowitz and Y. S. Horowitz, "Elimination of the residual signal in LiF:Cu,Mg,P," Radiation Protection Dosimetry, vol. 40, no. 4, pp. 265-269, 1992.

[5] Z. Zha, S. Wang, W. Shen, J. Zhu, and G. Cai, "Preparation and characteristics of LiF:Mg,Cu,P thermoluminescent material," Radiation Protection Dosimetry, vol. 47, no. 1-4, pp. 111-118, 1993.

[6] R. R. Patil and S. V. Moharil, "On the role of copper impurity in LiF:Mg,Cu,P phosphor," Journal of Physics: Condensed Matter, vol. 7, no. 50, article 025, pp. 9925-9933, 1995.
[7] S. S. Shinde, B. S. Dhabekar, T. K. Gundu Rao, and B. C. Bhatt, "Preparation, thermoluminescent and electron spin resonance characteristics of LiF:Mg, Cu,P phosphor," Journal of Physics D, vol. 34, no. 17, pp. 2683-2689, 2001.

[8] T.-C. Chen and T. G. Stoebe, "Influence of annealing on kinetic trapping parameters in $\mathrm{LiF}: \mathrm{Mg}, \mathrm{Cu}, \mathrm{P}$ thermoluminescent phosphors," Radiation Measurements, vol. 29, no. 1, pp. 39-44, 1998.

[9] P. Bilski, M. Budzanowski, and P. A. Olko, "A systematic evaluation of tee dependence of glow curve structure on the concentration of dopants in LiF:Mg,Cu,P," Radiation Protection Dosimetry, vol. 65, no. 1-4, pp. 195-198, 1996.

[10] P. Bilski, M. Budzanowski, P. A. Olko, and M. P. R. Waligórski, "Influence of concentration of magnesium on the dose response and let-dependence of TL efficiency in LiF:Mg,Cu,P (MCP-N) detectors," Radiation Measurements, vol. 29, no. 3-4, pp. 355359, 1998.

[11] S. W. S. McKeever, "Measurements of emission spectra during thermoluminescence (TL) from $\operatorname{LiF}(\mathrm{Mg}, \mathrm{Cu}, \mathrm{P}) \mathrm{TL}$ dosimeters," Journal of Physics D, vol. 24, no. 6, p. 988, 1991.

[12] N. Salah, P. D. Sahare, and A. A. Rupasov, "Thermoluminescence of nanocrystalline LiF:Mg, Cu, P," Journal of Luminescence, vol. 124, no. 2, pp. 357-364, 2007.

[13] M. Kumar, F. Singh, S. A. Khan et al., "Swift heavy ion induced structural and optical modifications in LiF thin film," Journal of Physics D, vol. 38, no. 4, pp. 637-641, 2005.

[14] M. Kumar, F. Singh, S. A. Khan, A. Tripathi, D. K. Avasthi, and A. C. Pandey, "Photoluminescence properties of $\mathrm{SHI}$ induced $\mathrm{F}_{2}$ and $\mathrm{F}_{3}^{+}$color centers in nano-granular LiF thin films," Journal of Luminescence, vol. 127, no. 2, pp. 302-306, 2007.

[15] V. A. Skuratov, S. M. Abu AlAzm, and V. A. Altynov, "Luminescence of aggregate centers in lithium fluoride irradiated with high energy heavy ions," Nuclear Instruments and Methods in Physics Research B, vol. 191, no. 1-4, pp. 251-255, 2002.

[16] A. Belarouci, F. Menchini, H. Rigneault et al., "Spontaneous emission properties of color centers based optical microcavities," Optics Communications, vol. 189, no. 4-6, pp. 281-287, 2001.

[17] G. Baldacchini, E. de Nicola, R. M. Montereali, A. Scacco, and V. Kalinov, "Optical bands of $\mathrm{F}_{2}$ and $\mathrm{F}_{3}^{+}$centers in LiF," Journal of Physics and Chemistry of Solids, vol. 61, no. 1, pp. 21-26, 2000.

[18] N. Salah, S. S. Habib, Z. H. Khan, and N. D. Alharbi, "Synthesis and characterization of pure and $\mathrm{Tb} / \mathrm{Cu}$ doped $\mathrm{Alq}_{3}$ nanostructures," Journal of Luminescence, vol. 143, pp. 640-644, 2013.

[19] N. D. Alharbi, N. Salah, S. S. Habib, and E. Alarfaj, "Synthesis and characterization of nano- and microcrystalline cubes of pure and Ag-doped LiF," Journal of Physics D, vol. 46, no. 3, Article ID 035305, 2013.

[20] F. Somma, R. M. Montereali, M. A. Vincenti, S. Polosan, and M. Secu, "Radiation induced defects in $\mathrm{Pb}^{2+}$-doped LiF crystals," Physics Procedia, vol. 2, no. 2, pp. 211-221, 2009.

[21] A. K. Parchur, A. I. Prasad, A. A. Ansari, S. B. Rai, and R. S. Ningthoujam, "Luminescence properties of $\mathrm{Tb}^{3+}$-doped $\mathrm{CaMoO}_{4}$ nanoparticles: annealing effect, polar medium dispersible, polymer film and core-shell formation," Dalton Transactions, vol. 41, pp. 11032-11045, 2012.

[22] S. Sato, S. Kamei, K. Uematsu et al., "Synthesis and luminescence properties of rare earth doped $\mathrm{Na}_{3} \mathrm{AlP}_{3} \mathrm{O}_{9} \mathrm{~N}$ oxynitridophosphate phosphor," Journal of Ceramic Processing Research, vol. 14, no. 1, pp. s74-s76, 2013.

[23] K. Sivaiah and S. Buddhudu, "Light-emission in $\mathrm{Tb}^{3+}$ and $\mathrm{Eu}^{3+}$ : PVP polymer films," Indian Journal of Pure and Applied Physics, vol. 49, no. 6, pp. 377-381, 2011. 
[24] J. Hao, M.-J. Han, Z. Xu, J. Li, and X. Meng, "Fabrication and evolution of multilayer silver nanofilms for surface-enhanced Raman scattering sensing of arsenate," Nanoscale Research Letters, vol. 6, article 263, 2011.

[25] P. Piasecki, A. Piasecki, Z. Pan, R. Mu, and S. H. Morgan, "Formation of Ag nanoparticles and enhancement of $\mathrm{Tb}^{3+}$ luminescence in $\mathrm{Tb}$ and $\mathrm{Ag}$ co-doped lithium-lanthanumaluminosilicate glass," Journal of Nanophotonics, vol. 4, no. 1, Article ID 043522, 2010.

[26] P. V. Ben and P. T. Tue, "The role of color luminescence centers $\mathrm{Mn}, \mathrm{Cu}$, Co in the semicondutors with wide band gap $\mathrm{ZnS}, \mathrm{ZnO}$ and their applications," VNU Journal of Science, vol. 24, pp. 181$187,2008$.

[27] Y. Li, Y. Chang, Y. Lin, Y. Chang, and Y.-J. Lin, "Synthesis and luminescent properties of $\mathrm{Ln}^{3+}\left(\mathrm{Eu}^{3+}, \mathrm{Sm}^{3+}, \mathrm{Dy}^{3+}\right)$-doped lanthanum aluminum germanate $\mathrm{LaAlGe}_{2} \mathrm{O}_{7}$ phosphors," Journal of Alloys and Compounds, vol. 439, no. 1-2, pp. 367-375, 2007.

[28] M. W. Blair, L. G. Jacobsohn, B. L. Bennett et al., "Structure and Luminescence of Ce-doped $\mathrm{Lu}_{2} \mathrm{SiO}_{5}$ Nanophosphor," Materials Research Society Symposia Proceedings, vol. 1056, 2008. 

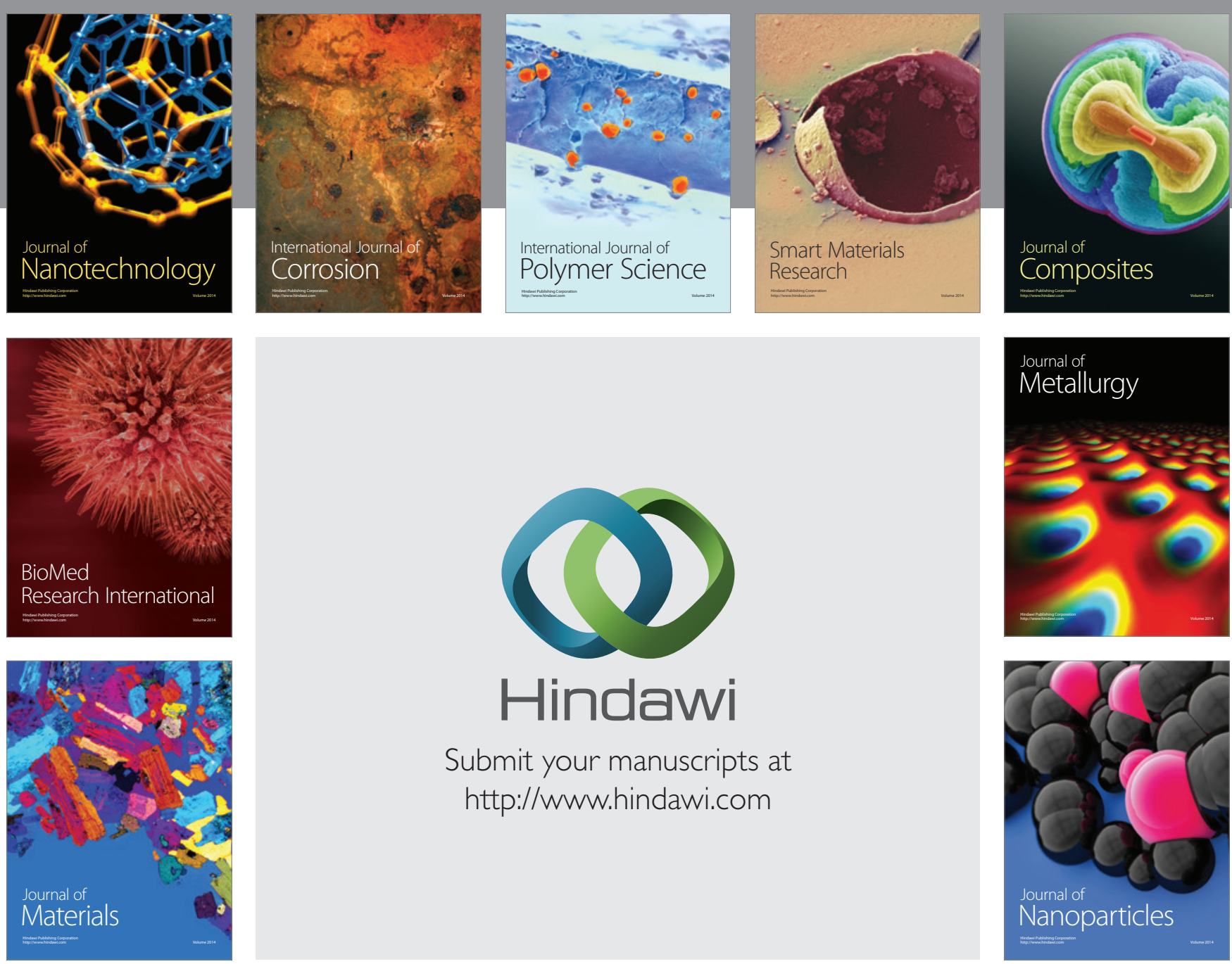

Submit your manuscripts at http://www.hindawi.com
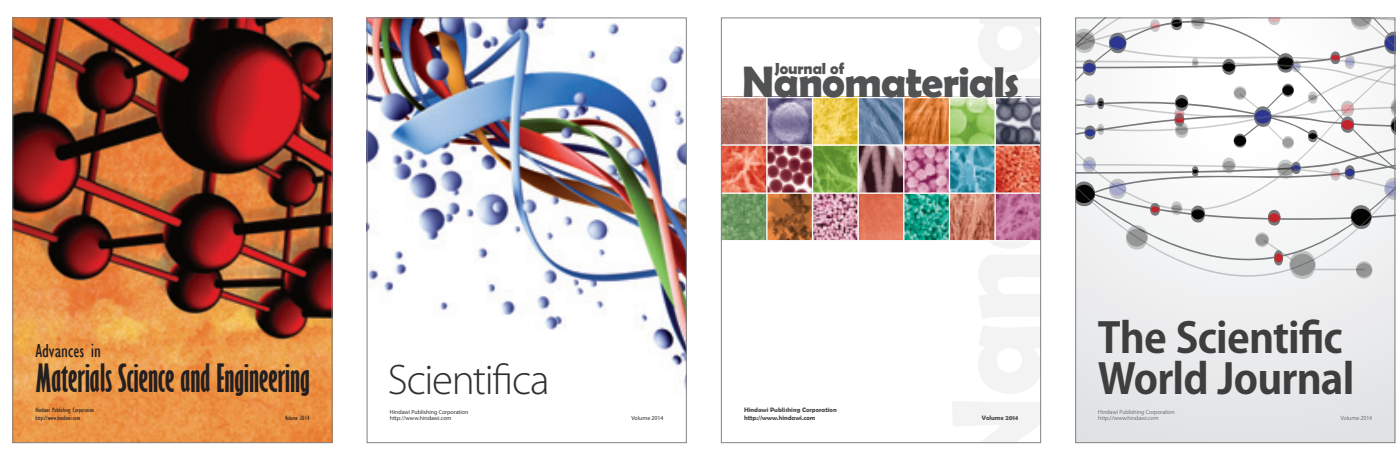

\section{The Scientific World Journal}
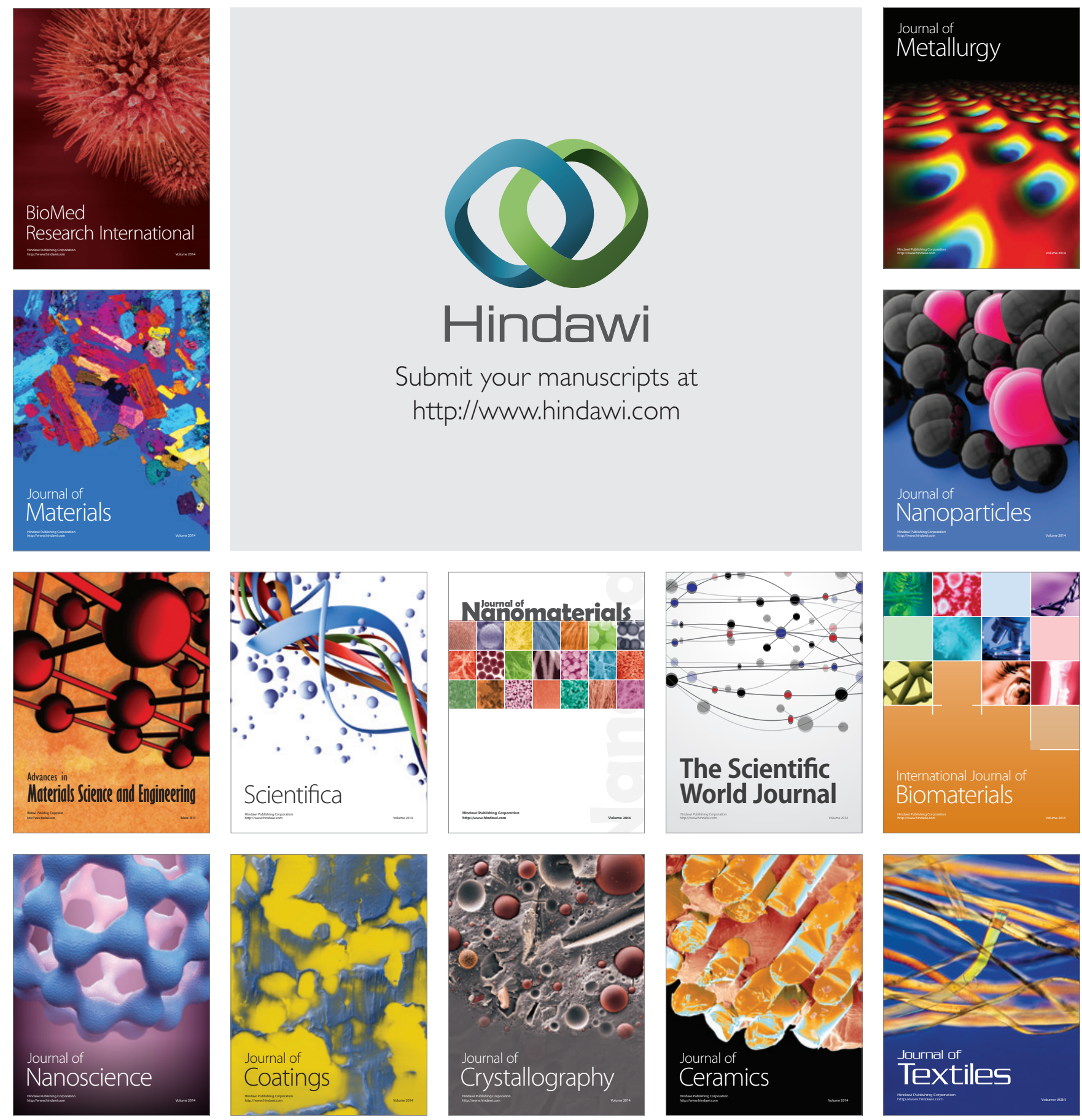